\title{
Electronic cigarette use and perceptions amongst UK medical students: A cross-sectional study
}

\author{
Medhia Afzal', Martha Ellis-Parkinson', Luke Holdsworth², Dominic L. Sykes², Michael G. Crooks ${ }^{1,2}$
}

\section{Dear Editor,}

We report a first of its kind survey of medical students in the UK, assessing tobacco and e-cigarette consumption, beliefs about e-cigarettes and smoking cessation curriculum assessment. All healthcare professionals have a role in promoting smoking cessation, with rates improved by the quality of advice offered and by combining pharmacotherapy and behavioral support ${ }^{1,2}$. Medical students, as future clinicians, will play a critical role in smoking cessation efforts. We conducted a cross-sectional study between 5 December 2019 and 6 February 2020 in which a 20 -item (19 multiple choice and 1 free text) questionnaire was distributed to 9 UK medical schools. A total of 188 responses were received encompassing all distributed medical schools. Current or past e-cigarette use was reported by $32.6 \%$ with $4.3 \%(n=8)$ using e-cigarettes daily and $1.1 \%(n=2)$ using e-cigarettes weekly; $8.5 \%(n=16)$ reported having tried or regularly using an e-cigarette, having never tried smoking tobacco; and $20 \%(n=2)$ of regular e-cigarette users had never smoked tobacco.

With regard to smoking cessation and education, e-cigarettes were considered beneficial for reducing traditional cigarette use by $89.9 \%$ of respondents and $56.1 \%$ would recommend them to patients for this purpose. When asked how addictive e-cigarettes are compared to traditional cigarettes, $64.9 \%(n=122)$ felt they were 'equally addictive' or 'more addictive' than tobacco. Of these, $35.2 \%$ $(n=43)$ identified as regular or previous e-cigarette users. Participant responses are detailed in Table 1.

When asked if their medical school curriculum provided sufficient education regarding tobacco and e-cigarettes, $46.8 \%(n=88)$ of students felt that it did. However, when answering to the question 'Would you feel comfortable advising a patient about the use of e-cigarettes?', $60.6 \%(n=114)$ responded 'no, not confident in doing so'. There was a difference in confidence level noted between those at early and late stages of medical school with $52.0 \%(n=13)$ of final year students not feeling confident advising patients compared with $73.3 \%(n=63)$ of students in their first and second year $\left(\mathrm{p}=0.044, \chi^{2}\right.$ test $)$.

Through this study, we have identified that despite an overwhelming majority believing e-cigarettes are useful for reducing tobacco consumption, many would not recommend them to patients for this purpose and the majority lack confidence to advise patients about their use. This is consistent with US data ${ }^{3,4}$. We also reveal a belief among medical students that e-cigarettes are harmful with more than 1 in 4 believing e-cigarettes to be at least as harmful as tobacco. Respiratory disease was the most commonly reported perceived health risk, with $81 \%(n=152)$ of respondents citing this as a concern. This is at odds with Public Health England's guidance stating e-cigarettes to be ' $95 \%$ less harmful than cigarette smoking'5. Many students felt that they have not received sufficient
AFFILIATION

1 Hull York Medical School, Hull, United Kingdom

2 Respiratory Research Group, Hull and East Yorkshire Hospitals NHS Trust, Hull, United Kingdom

\section{CORRESPONDENCE TO}

Luke Holdsworth. Respiratory Research Group, Hull and East Yorkshire Hospitals NHS Trust, Hull, HU16 5JQ, United Kingdom. E-mail: luke.holdsworth@hey.nhs.uk

\section{KEYWORDS}

e-cigarette, medical student, smoking cessation, medical school curriculum

Received: 1 December 2020 Accepted: 19 December 2020 
Table 1. Distribution of participants' responses (\%) to questions asked in the survey, stratified by medical school year

\begin{tabular}{|c|c|c|c|c|c|c|c|c|}
\hline & Response & $\begin{array}{l}\text { All } \\
\text { respondents } \\
(\mathbf{N}=188\end{array}$ & $\begin{array}{l}\text { Year } 1 \\
(n=52)\end{array}$ & $\begin{array}{l}\text { Year } 2 \\
(n=34)\end{array}$ & $\begin{array}{l}\text { Year } 3 \\
(n=26)\end{array}$ & $\begin{array}{l}\text { Year } 4 \\
(n=39)\end{array}$ & $\begin{array}{l}\text { Years } 5 \& 6 \\
\qquad(n=25)\end{array}$ & $\begin{array}{l}\text { Intercalated } \\
\text { students } \\
(n=12)\end{array}$ \\
\hline \multicolumn{9}{|l|}{ Perceived risks and benefits } \\
\hline \multirow{2}{*}{$\begin{array}{l}\text { Do you believe e-cigarettes are } \\
\text { harmful to those who use them? }\end{array}$} & Yes & 93.1 & 94.2 & 94.1 & 84.6 & 92.3 & 96.0 & 100.0 \\
\hline & No & 6.9 & 5.8 & 5.9 & 15.4 & 7.7 & 4.0 & 0.0 \\
\hline \multirow{2}{*}{$\begin{array}{l}\text { Do you believe e-cigarettes are } \\
\text { harmful to people that are near users } \\
\text { or those that are passively exposed? }\end{array}$} & Yes & 47.3 & 57.7 & 41.2 & 50.0 & 43.6 & 44.0 & 33.3 \\
\hline & No & 52.7 & 42.3 & 58.8 & 50.0 & 56.4 & 56.0 & 66.7 \\
\hline \multirow{3}{*}{$\begin{array}{l}\text { How harmful do you consider } \\
\text { e-cigarettes to be in comparison to } \\
\text { traditional cigarettes? }\end{array}$} & More harmful & 1.6 & 3.8 & 0.0 & 3.8 & 0.0 & 0.0 & 0.0 \\
\hline & Less harmful & 73.4 & 61.5 & 76.5 & 80.8 & 82.1 & 76.0 & 66.7 \\
\hline & Equally harmful & 25.0 & 34.7 & 33.5 & 15.4 & 17.9 & 24.0 & 33.3 \\
\hline \multirow{3}{*}{$\begin{array}{l}\text { Do you think it is safe for pregnant } \\
\text { women to use e-cigarettes? }\end{array}$} & Yes & 3.2 & 0.0 & 8.8 & 0.0 & 2.5 & 4.0 & 8.3 \\
\hline & No & 67.0 & 75.0 & 55.9 & 65.4 & 66.7 & 72.0 & 58.4 \\
\hline & Don't know & 29.8 & 25.0 & 35.3 & 34.6 & 30.8 & 24.0 & 33.3 \\
\hline \multicolumn{9}{|l|}{ Cessation and education } \\
\hline \multirow{2}{*}{$\begin{array}{l}\text { Do you believe e-cigarettes are useful } \\
\text { for reducing tobacco consumption } \\
\text { (e.g. smoking traditional cigarettes)? }\end{array}$} & Yes & 89.8 & 90.4 & 91.2 & 92.3 & 94.9 & 80.0 & 83.3 \\
\hline & No & 10.2 & 9.6 & 8.8 & 7.7 & 5.1 & 20.0 & 16.7 \\
\hline \multirow{2}{*}{$\begin{array}{l}\text { Would you recommend the use of } \\
\text { e-cigarettes to a patient to quit } \\
\text { tobacco smoking? }\end{array}$} & Yes & 56.1 & 46.2 & 61.8 & 69.2 & 51.3 & 60.0 & 58.3 \\
\hline & No & 43.9 & 53.8 & 38.2 & 30.8 & 48.7 & 40.0 & 41.7 \\
\hline \multirow{4}{*}{$\begin{array}{l}\text { How addictive do you feel that } \\
\text { e-cigarettes are compared to } \\
\text { traditional cigarettes? }\end{array}$} & More addictive & 12.8 & 15.4 & 11.8 & 11.5 & 12.8 & 12.0 & 8.3 \\
\hline & Less addictive & 18.1 & 13.5 & 17.6 & 23.1 & 25.6 & 16.0 & 8.3 \\
\hline & Equally addictive & 52.1 & 57.6 & 55.9 & 50.0 & 38.5 & 52.0 & 66.7 \\
\hline & Don't know & 17.0 & 13.5 & 14.7 & 15.4 & 23.1 & 20.0 & 16.7 \\
\hline \multirow{2}{*}{$\begin{array}{l}\text { Do you feel that you are sufficiently } \\
\text { educated regarding e-cigarettes at } \\
\text { your medical school? }\end{array}$} & Yes & 46.5 & 50.0 & 47.1 & 50.0 & 43.6 & 40.0 & 41.7 \\
\hline & No & 53.5 & 50.0 & 52.9 & 50.0 & 56.4 & 60.0 & 58.3 \\
\hline \multirow{2}{*}{$\begin{array}{l}\text { Would you feel comfortable } \\
\text { advising a patient about the use of } \\
\text { e-cigarettes? }\end{array}$} & Yes & 38.9 & 22.2 & 35.3 & 57.7 & 50.0 & 48.0 & 33.3 \\
\hline & No & 61.1 & 77.8 & 64.7 & 42.3 & 50.0 & 52.0 & 66.7 \\
\hline
\end{tabular}

teaching about e-cigarettes at medical school. As a cohort of the population that is pivotal in reducing the use of tobacco in the future, there is a need to address deficiencies in knowledge and confidence advising patients about e-cigarettes. We believe that our data provide meaningful insights about UK medical students' knowledge and perceptions about e-cigarettes and should prompt medical schools to consider their course content on smoking cessation and e-cigarettes.

\section{REFERENCES}

1. Stead LF, Buitrago D, Preciado N, et al. Physician advice for smoking cessation. Cochrane Database Syst Rev. 2013;2013(5):CD000165. doi:10.1002/14651858. CD000165.pub4

2. Stead LF, Lancaster T. Combined pharmacotherapy and behavioural interventions for smoking cessation. Cochrane Database Syst Rev. 2012;10:CD008286. doi:10.1002/14651858.CD008286.pub2

3. Hinderaker K, Power D, Allen S, et al. What do medical students know about e-cigarettes? A cross-sectional survey from one U.S. medical school. BMC Med Educ. 2018;18:32. doi:10.1186/s12909-018-1134-1

4. Zhou S, van Devanter N, Fenstermaker M, et al. A Study of the Use, Knowledge, and Beliefs about Cigarettes and Alternative Tobacco Products among Students at One U.S. Medical School. Acad Med. 2015;90(12):1713-1719. 
doi:10.1097/ACM.0000000000000873

5. Public Health England. E-cigarettes: an evidence update A report commissioned by Public Health England. [Facebook page]. www.facebook.com/PublicHealthEngland. Published 2015. Accessed September 2, 2020.

CONFLICTS OF INTEREST

The authors have completed and submitted the ICMJE Form for Disclosure of Potential Conflicts of Interest and none was reported.

FUNDING

There was no source of funding for this research.

PROVENANCE AND PEER REVIEW

Not commissioned; internally peer reviewed. 